\title{
La redención del pasado. Sobre un motivo central del pensamiento de Walter Benjamin
}

\section{The redemption of the past. On a main motif in Walter Benjamin's work}

\author{
José Luis Delgado \\ Universidad de Barcelona
}

Recibido: 21-10-2014

Aceptado: 21-06-2015

\section{Resumen}

El presente trabajo examina la reflexión de Walter Benjamin en torno a la categoría de "redención", desarrollada principalmente en las tesis Sobre el concepto de historia. Para ello, en primer lugar llevaremos a cabo una reconstrucción de la crítica del "destino", que Benjamin proyecta en los años veinte sobre el ámbito del derecho, la economía y, especialmente, la historia. La crítica a la lógica expiatoria del "destino" - elaborada en ensayos como Destino y carácter, Hacia la crítica de la violencia o Capitalismo como religión - nos ofrecerá entonces una vía privilegiada para mostrar la estructura "dialéctica" de la redención, con la que Benjamin moviliza su anterior teoría del conocimiento contra la doctrina del progreso.

Palabras clave: Benjamin, capitalismo, culpa, destino, dialéctica, progreso, redención.

\section{Abstract}

The following paper examines Walter Benjamin's reflection on the category of "redemption", mainly developed in the theses On the concept of History. To this end, we will try firstly to reconstruct Benjamin's critique of "fate", as it unfolds in the twenties on the field of right, economy and, especially, history. The critique of the expiatory logic of "fate" - developed in essays such as Fate and Character, 
Critique of violence or Capitalism as religion - will then allow us to disclose the "dialectical" structure of redemption, whereby Benjamin mobilizes his previous theory of knowledge against the doctrine of progress.

Keywords: Benjamin, capitalism, dialectics, fate, guilt, progress, redemption.

\section{Historia y redención}

Frente a la obra de Walter Benjamin caben, en principio, dos actitudes distintas. Por un lado, la que identifica los objetos de pensamiento que transitan por sus textos (el lenguaje, la obra de arte, la técnica o la historia), aun a riesgo de reafirmar la difundida imagen de su obra como una amalgama de intereses heterogéneos. O, por otro lado, la que persigue el gesto de pensamiento que atraviesa sus controvertidas tesis sobre uno u otro objeto, haciéndolas posibles. El presente trabajo toma partido por la segunda opción y, en consecuencia, examina la reflexión histórica benjaminiana con el propósito de mostrar el gesto "dialéctico" que tensa su pensamiento en dos extremos opuestos: un momento destructivo y un momento constructivo, la crítica del "falso" orden constructivo (se llame "destino", "derecho", "religión" o "progreso") y la exposición de la "verdadera"1 unidad de los fenómenos. Esta unidad "verdadera" no es el resultado de una mera proyección subjetiva sobre las cosas sino que se halla inscrita en los propios fenómenos, aunque a la vez no se confunde con ellos, simultáneamente presente y ausente de su superficie empírica. Un mismo trazo sinuoso recorre la reflexión de Benjamin sobre la historia: desde la teoría "dialéctica"2 del conocimiento desarrollada en el prólogo del libro sobre el Barroco - cuyo eje central era la noción de "representación" de la "idea" - pasando por la noción de "imagen" o "construcción"3, elaboradas durante los años treinta, hasta las tesis Sobre el concepto de historia (1939-40), donde la noción clave de "redención" vuelve a mostrar de nuevo una matriz "dialéctica".

Esto último resulta especialmente apreciable en la tesis II, donde convergen dos líneas de reflexión que Benjamin había desarrollado en su obra anterior: la crítica al carácter "concluso"4 y definitivo del pasado - expuesta en el ensayo sobre

\footnotetext{
${ }^{1}$ La oposición entre la "falsa" y la "verdadera unidad" de los fenómenos se encuentra en el prólogo epistemo-crítico del libro sobre el Barroco (Gesammelte Schriften vol. I, 1, p. 213). En adelante citado como GS, seguido del número del volumen y página (las traducciones son nuestras salvo indicación expresa).

2 Tiedemann, R., Studien zur Philosophie Walter Benjamins. Frankfurt am Main: Suhrkamp, 1973, p. 84.

3 Sobre la continuidad entre la noción de "representación" y la de "construcción" véase Steiner, U., "Das 'Höchste wäre: zu begreifen, daß alles Fachtische schon Theorie ist'. Walter Benjamin ließt Goethe", en Zeitschrift für deutsche Philologie, 121, 2002, pp. 276-277.
}

4 GS II, 1, p. 477. 
Eduard Fuchs (1937) - y la crítica al "destino" - elaborada en un conjunto de ensayos de los años veinte. Como trataremos de mostrar, lo que anuda estas dos críticas es precisamente el concepto de "redención". Benjamin elabora la noción de "redención" en oposición frontal a la concepción de la historia que mantiene la filosofía del progreso:

"Una de las peculiaridades más notables del temple humano", dice Lotze, "junto a tanto egoísmo en lo individual, es la general falta de envidia de todo presente respecto a su futuro". Tal reflexión nos lleva a que la imagen de felicidad que cultivamos esté teñida enteramente por el tiempo al que el decurso de nuestra existencia nos ha asignado de una vez por todas. Felicidad que pudiera despertar en nosotros envidia solo la hay en el aire que hemos respirado, con hombres con los que hubiéramos podido conversar, con mujeres que hubiesen podido entregársenos. En otras palabras, en la idea de felicidad resuena inevitablemente la de redención. ${ }^{5}$

Este pasaje de la tesis II es en realidad una versión ligeramente modificada de un fragmento incluido previamente en el Passagen-Werk y perteneciente a un conjunto de citas de la obra de Hermann Lotze 6 . Benjamin comparte claramente el intento de Lotze de oponerse al tipo de "redención" que defiende la doctrina del progreso, ya que implica una instrumentalización intolerable del sufrimiento de las generaciones pasadas en aras de la felicidad de las futuras:

Resulta inquietante... el pensamiento de que la civilización está repartida entre las sucesivas generaciones, de modo que las últimas gozan del fruto crecido del esfuerzo sin recompensa, y a menudo de la miseria, de las anteriores. [...] Considerar que sólo progresa la humanidad en general supone apartar la vista de todo su infortunio... No puede haber progreso alguno... mientras no se incremente la felicidad y plenitud de las mismas almas que antes padecieron bajo un estado carente de plenitud. ${ }^{7}$

La concepción según la cual el dolor experimentado por una generación puede ser compensado por la felicidad de la siguiente es ilusoria, dado que la única compensación real de un sufrimiento es la que proviene de la felicidad que cada generación sea capaz de procurarse dentro del tiempo limitado de su existencia, sin la mediación de "la" historia, elevada al rango de singular colectivo. La redención,

\footnotetext{
5 GS I, 2, p. 693; trad. esp. de A. Brotons Muñoz, Obras. Libro I/vol. 2. Madrid: Abada, 2008, p. 306. 6 GS V, 1, p. 600 (N13a, 1). Tal como Benjamin escribe a Horkheimer, "la destrucción de la idea de una continuidad de la cultura, que fue postulada en el ensayo sobre Fuchs, debe tener consecuencias epistemológicas, entre las cuales una de las más importantes es la determinación de los límites en el uso del concepto de progreso. Para mi sorpresa encontré en Lotze una línea de reflexión que proporciona apoyo a mis consideraciones" (Gesammelte Briefe, vol. VI, p. 198 [carta del 24/1/1939]). En adelante citado como GB, seguido del número del volumen y página.

7 GS V, 1, p. 599 (N13, 3); trad. esp. Libro de los Pasajes. Madrid: Akal, 2011, p. 481.
} 
tal como la entiende la filosofía del progreso, es una operación de canje entre la infelicidad del pasado y la felicidad del futuro. Pero para poder llevar a cabo este intercambio hay que presuponer una especie de sujeto colectivo en el que se hallarían fusionadas las diferentes generaciones y que funcionaría entonces como portador único de la felicidad e infelicidad que afecta a cada uno de sus momentos parciales.

El "falso" orden constructivo de la historia que consiste en la compensación entre generaciones se basa en un modelo jurídico ${ }^{8}$. La filosofía idealista moderna, por ejemplo, está llena de motivos procedentes del ámbito de la jurisprudencia. Es el caso de la "deducción" trascendental, donde Kant empleaba un término técnico que designa metafóricamente el "proceso" a través del cual el "tribunal de la razón" se vuelve capaz de "juzgar" sobre la verdad o legitimidad (quaestio iuri) de un conjunto de hechos (quaestio facti) ${ }^{9}$. El influjo del componente procesal en las filosofías modernas de la historia puede reconocerse en la llamada "tribunalización"10 de la historia, es decir, su conversión en un tribunal que trasciende la facticidad de los acontecimientos históricos para dirimir la cuestión de su legitimidad. Los hechos no se reducen a su positividad dada e irrevocable sino que además poseen un significado que depende del lugar que ocupan en el contexto más amplio de una "deducción" o "proceso" capaz de "positivizar el mal"11. Por tanto, el daño sufrido en el pasado no es definitivo y puede ser modificado a través de su redescripción como instrumento de un bien mayor. La totalidad de la historia, erigida en tribunal de sus momentos parciales, "temporaliza"12 la compensación, dado que ya no compensa el mal presente remitiendo a un bien trascendente sino a un más allá intramundano, la felicidad futura. El progreso se convierte así en una teodicea inmanente: la justificación del orden moral de la historia13.

Por lo tanto, Benjamin opone en el Passagen-Werk y las Tesis el "progreso" a la "redención", es decir, el nexo expiatorio entre generaciones a un vínculo entre pasado y presente que es ajeno tanto a la culpa como a la expiación. Dicha oposi-

\footnotetext{
8 El núcleo jurídico de esta concepción de la historia aparece ya en un breve fragmento juvenil (19181919), donde Benjamin reúne bajo una misma columna la "historia universal" (Weltgeschichte) y la “justicia universal” (Weltgericht) - que es el término en alemán para designar el "juicio final”. A estos dos términos contrapone en otra columna la "historia divina" (GS VI, p. 91).

9 Marquard, O., Las dificultades con la filosofía de la historia. Valencia: Pre-Textos, 2007, p. 49 y p. 67.

10 Marquard, O., Apología de lo contingente. Valencia: Edicions Alfons el Magnànim, 2000, p. 78.

11 ivi, p. 76.

12 ivi, p. 42.

13 Yendo más lejos, Jan Assmann se remonta hasta la antigüedad para mostrar la influencia de las instituciones jurídicas sobre los orígenes de la historiografía. La narración de la historia surge con la descripción del nexo entre acción y resultado en los términos de un "justicia conectiva" que asocia la culpa al castigo, según una "semiotización" de los acontecimientos que privilegia el sentido a la causalidad. Cfr. Historia y mito en el mundo antiguo. Madrid: Gredos, 2011, pp. 209-233.
} 
ción muestra una cierta continuidad con ciertos elementos teóricos de su obra anterior, muy especialmente con la crítica al "destino" realizada durante los años veinte en un conjunto de ensayos afines. Como veremos en la siguiente sección, Benjamin analiza el "destino" como una máquina compensatoria cuyo funcionamiento detecta en diferentes ámbitos: el derecho, la economía y, sobre todo, la historia. En este sentido, la oposición entre el orden del "destino" y las diferentes figuras con las que Benjamin alude a una liberación o una felicidad posibles (como el "carácter" o la "violencia divina") prefigura la oposición tardía entre progreso y redención. Sin embargo, en el último tramo de su obra Benjamin introdujo un importante desplazamiento a este esquema previo, de forma que a la falsa construcción del destino no opondrá ya un gesto meramente destructivo sino una forma alternativa de construcción histórica, para la cual reserva el nombre de "redención" (cfr. sección III).

\section{La redención como nihilismo destructivo}

\subsection{El destino como derecho}

La crítica de Benjamin a la "falsa" totalidad de la historia que erige la doctrina del progreso prosigue, en realidad, la reflexión sobre el tiempo mítico del destino iniciada en Destino y carácter (1919). Los términos "destino" y "carácter" hacen referencia a dos "prácticas interpretativas" 14 que trascienden lo visible para descifrar en los hechos un signo de algo otro. Como la "quiromancia", que lee el destino en las líneas de la mano, o la "fisiognómica", que lee el carácter moral de un individuo en sus rasgos físicos, se trata de disciplinas hermenéuticas ya que "el nexo entre el signo y lo designado"15 no tiene nada que ver con los "nexos causales" sino con "un nexo semántico". En este tipo de prácticas las cosas remiten unas a otras en virtud del significado que expresan, no de las propiedades físicas que poseen.

Los diferentes contextos en los que estas dos disciplinas han sido tradicionalmente clasificadas (la esfera religiosa, en el caso del "destino", y la esfera ética, en el del "carácter") han difuminado sus diferencias conduciendo a una especie de identificación. El propósito de Benjamin es invertir esta situación, es decir, recuperar la diferencia entre ambas prácticas mostrando su pertenencia común a la esfera "natural", en su ambigüedad constitutiva de naturaleza caída y abandonada por la gracia y, a la vez, de naturaleza pura de la creación antes de la caída ${ }^{16}$. Al ser recon-

\footnotetext{
14 GS II, 1, p. 176; trad. esp. de J. Navarro Pérez, Obras. Libro II /vol. 2. Madrid: Abada, 2007, p. 180.

15 GS II, 1, p. 172.

16 Se trata de la misma ambigüedad que en el libro sobre el Barroco afecta a la noción de "historia natural", y que se expresa terminológicamente en la diferencia entre la "natürliche Historie" (GS I, 1,
} 
ducidas a esta esfera, "destino" y "carácter" aparecen como dos modos opuestos de ubicación del hombre en el contexto "natural": la sumisión a una inmanencia sin afuera o la apertura de una brecha hacia la trascendencia. En otras palabras, se trata de una oposición entre el confinamiento bajo la "falsa" construcción de un orden sin excepciones y la destrucción de ese orden.

Bajo la óptica del destino los hechos no aparecen meramente como hechos sino como signos que, resignificados bajo las categorías de la "culpa" (Schuld) y la "reparación"17 (Sühne), remiten unos a otros mediante un nexo "semántico" de compensación. "La desdicha destinal suele considerarse la respuesta de Dios o los dioses frente a la culpa religiosa" 18 . Pero aunque en la esfera religiosa toda culpa debe ser reparada con la desdicha (Unglück), a esta esfera pertenece igualmente la posibilidad de una felicidad (Glück) concedida por los dioses para liberar a los hombres de "la concatenación de los destinos y de la red misma del propio destino"19. En la religión existe todavía un afuera del destino, la felicidad, que no debe entenderse como liberación de la culpa por medio de la expiación sino como liberación del propio "nexo de culpa" 20. La felicidad interrumpe la construcción interpretativa del destino (el nexo culpa-desdicha) y suspende así la compulsión a interpretar y determinar las propias acciones en los términos de una ley externa que fija una compensación para cada culpa.

El destino, hasta ahora ubicado erróneamente en la esfera de la religión, debe ser reconducido a la esfera del derecho, cuya esencia es preservar "la concatenación de culpa y expiación" 21 . Aunque el derecho, más que preservarla, lo que hace es producirla: la vida es algo que "primero fue ya condenado y, a continuación, se hizo culpable [...] Puede el juez ver destino donde quiera; al castigar, lo dicta ciegamente"22. El derecho, en tanto que "práctica interpretativa", debe entenderse no en función de la verdad preexistente que constata sino del efecto performativo que pro-

p. 227) y la "Naturgeschichte" (GS I, 1, p. 269). Mientras la primera designa el estado inmóvil y atemporal previo a la caída en la temporalidad profana, la segunda hace referencia a la experiencia barroca de la caducidad y ausencia de telos de la historia. Sobre la noción de "natürliche Historie" véase Hanssen, B., "Philosophy at Its Origin: Walter Benjamin's Prologue to the Ursprung des deutschen Trauerspiels", en Modern Language Notes, vol. 110, No. 4, September 1995, p. 812. Sobre la ambivalencia de la noción de "naturaleza" en el libro sobre el Barroco véase Weigel, S., Walter Benjamin. Die Kreatur, das Heilige, die Bilder. Frankfurt am Main: Fischer, 2008, pp. 36-38.

17 El término Sühne significa castigo, pero en el sentido general de expiación, reparación, desagravio por un daño sufrido previamente. Este sentido se corresponde perfectamente con la ambigüedad semántica del término Schuld, que en alemán designa la "culpa" pero también la "deuda", es decir, la falta cometida como algo que exige ser saldado o compensado.

18 GS II, 1, p. 173.

19 GS II, 1, p. 174.

20 GS II, 1, p. 175.

21 ibidem; trad. esp. p. 178.

22 ibidem; trad. esp. p. 179. 
duce: el derecho no es un saber de la culpa a la que juzga sino una práctica que, por medio de la condena, produce la culpa que salda o repara. De esta manera, reproduce el nexo que dice respetar.

El pensamiento mítico invierte el orden lógico del razonamiento: no dice "existe la culpa y, por tanto, debe ser reparada" sino "debe existir un orden que repare las culpas y, por tanto, es necesario que existan culpables". Y si no existen será necesario crearlos a fin de mantener la ficción de totalidad del curso histórico. De ello se encarga la "inculpación jurídica"23 (rechtliche Verschuldung), que es a la vez un acto sobre el mundo y una interpretación de él, porque bajo el orden del destino el hombre no es juzgado culpable de un acto cometido antes sino en virtud de un acto que tiene lugar después, en la expiación que produce la culpa retrospectivamente.

A los ojos de Benjamin el derecho aparece como un mecanismo ineluctable de compensación. Para ilustrar la idea de una equivalencia o proporcionalidad entre culpa y castigo, condición necesaria de la compensación, Benjamin remite a la alegoría tradicional de la justicia, que "va depositando con cuidado culpa y expiación en los dos platillos de la balanza" 24 de forma que el "orden moral del mundo" 25 quede así "restablecido". Culpa y castigo se compensan como los pesos de una balanza, magnitudes equiparables dentro de un sistema métrico cerrado. De hecho, la "balanza" como símbolo del carácter compensatorio del derecho la había empleado ya Nietzsche en Aurora ${ }^{26}$ y, más adelante, también en La genealogía de la moral, que extiende esta lógica de la compensación a la esfera de la moral27. Benjamin seguirá ahondando en esta perspectiva en algunos trabajos contemporáneos a Destino y carácter, en los que detecta la presencia del orden mítico del destino en la esfera del derecho, la economía o la historia.

\subsection{El derecho como destino}

La máquina compensatoria del destino vuelve a ser objeto de reflexión en Hacia la crítica de la violencia (1921), que prosigue la reflexión sobre el derecho emprendida en Destino y carácter. El propósito de Kant en la Doctrina del derecho era fundar el derecho - las relaciones que regulan la posesión de bienes - en el imperativo

\footnotetext{
23 GS II, 1, p. 174.

24 GS II, 1, p. 175; trad. esp. p. 179.

25 ibidem.

26 Nietzsche describe el código penal "con su balanza de tendero y su voluntad de compensar el delito con la pena" (Nietzsche, F., Aurora. Meditaciones sobre los prejuicios morales. Palma de Mallorca: Jose J. de Olañeta, 2003, p. 158).

${ }^{27}$ Nietzsche critica la moral como la actitud para la cual "todo perjuicio tiene en alguna parte su equivalente y puede ser realmente compensado" (Nietzsche, F., La genealogía de la moral. Madrid: Alianza, 2008, p. 83).
} 
categórico. Pero dado que el imperativo prohibía cualquier intromisión de la acción de un individuo en la esfera de acción de los demás, cualquier objeto de posesión, situado potencialmente en la zona de interferencia entre distintas esferas individuales, quedaba fuera del restrictivo alcance del imperativo. Para superar este impasse teórico Kant introdujo un postulado adicional, el derecho del individuo a tomar posesión de los bienes (la Gewalt), para a partir de él derivar el resto de derechos. Benjamin rechaza la solución kantiana, ya que antes de admitir como un derecho la facultad de Gewalt (en su ambigüedad constitutiva de "poder" y "violencia" al mismo tiempo) debe ser examinada en una nueva investigación "crítica", en sentido kantiano, que distinga cuando un acto de posesión es legítimo - "poder" - y cuando no - convirtiéndose en "violencia"28.

Tal investigación es emprendida en Zur Kritik der Gewalt, cuyo propósito principal es distinguir la violencia ilegítima - "mítica" o "destinal"29 - de la legítima "divina". Si en el derecho natural la legitimidad de la violencia derivaba de la legitimidad de un fin dado al que sirve de medio, para el derecho positivo, que no admite la legitimidad de fines naturales o extra-jurídicos, la legitimidad de la violencia solo puede derivar de su conformidad interna a los procedimientos jurídicos. Pero entonces ¿cómo es posible una legitimidad intra-jurídica de la violencia? Según Benjamin la única manera de concebir una violencia ajustada a derecho es concebirla como medio para el derecho mismo, lo que puede asumir dos formas: la violencia que "instaura derecho" (rechtsetzende) y la que "mantiene derecho" (rechtserhaltende).

En tanto que al derecho es consustancial la amenaza de la violencia, no pertenece en verdad a la esfera de la justicia sino a la del destino. El gesto es simétrico respecto al descrito en Destino y carácter: así como el destino debía ser transpuesto a la esfera del derecho, el derecho debe ahora ser reconducido a la esfera del destino. Derecho y destino remiten el uno al otro. Como señala Benjamin, para comprender el derecho es necesario realizar un "análisis de la esfera propia del destino, de la cual procede" 30 . El derecho es inseparable de la "amenaza jurídica" 31 , es decir, antes que nada es derecho a ejercer la violencia contra quien incumpla la ley, por eso la categoría central del derecho es el castigo. La amenaza que en el derecho pende continuamente sobre los hombres como una "presencia latente" 32 es la amenaza del castigo: el derecho garantiza que toda infracción de la ley será castigada

\footnotetext{
28 Para una reconstrucción del punto de partida kantiano del ensayo véase Fenves, P., The Messianic Reduction. Walter Benjamin and the Shape of Time. Stanford: Stanford University Press, 2011, pp. 190-209.

29 GS II, 1, p. 188.

30 ibidem; trad. esp. p. 191.

31 ibidem.

32 GS II, 1, p. 190; trad. esp. p. 194.
} 
sin excepciones. Esta clausura del nexo infracción-pena en un espacio sin exterioridad es lo que asemeja el derecho al destino.

Una prueba del carácter "destinal" del derecho lo ofrece "el ámbito de los castigos" 33 y, en especial, la pena de muerte. Benjamin ve en la máxima pena, que todavía contemplan los actuales códigos penales, un residuo de los orígenes arcaicos del derecho, las "relaciones jurídicas primitivas" (primitiven Rechtsverhältnissen) en las que "la pena de muerte se aplica también a los delitos contra la propiedad, con los que no parece guardar 'proporción'. Y es que su sentido no es castigar la infracción del derecho sino establecer el nuevo derecho" 34 . La falta de "relación" o "proporción" (Verhältnis) entre lo banal del delito y lo extremo de la pena revela el verdadero funcionamiento del derecho: el castigo no sirve para compensar una infracción sino para encadenar dos hechos cualesquiera mediante un constructo convencional. Instaurar y mantener esa "falsa" construcción es la verdadera finalidad del castigo. Por tanto, la reparación de las faltas no es el fin del derecho sino solo "un medio para fines jurídicos" 35 , es decir, para preservar el propio orden del derecho, erigido como un fin en sí mismo.

El castigo es, como el destino, una "práctica interpretativa", a la vez un saber y un poder. Es decir, introduce los hechos en una trama simbólica donde valen como magnitudes equiparables (la infracción y la pena), pero esa redescripción tiene lugar por medio de un acto práctico. Es lo que expresa Benjamin cuando afirma que el derecho se basa en "la exposición (Darstellung) y mantenimiento (Erhaltung) de un orden del destino"36. La indiferencia entre "exposición" teórica y "mantenimiento" práctico alude nuevamente al carácter performativo del derecho que, mediante la pena, produce el nexo jurídico que sanciona.

Como hemos visto, los dos tipos de violencia - la que "instaura" y la que "mantiene" derecho - forman parte del orden sin afuera del destino. Y, sin embargo, existe una diferencia crucial entre ambas. Si hay algo que no puede tolerar el derecho es la pena sin castigo, la "infracción" (Rechtsbruch), literalmente la ruptura o quiebra del derecho, ni siquiera momentánea, dado que una violencia lo bastante poderosa como para situarse fuera del alcance de la violencia del derecho vigente (el castigo) es seguramente lo bastante poderosa como para imponer otro derecho que lo sustituya (una nueva asignación de penas e infracciones).

Pero antes de que la violencia que ha logrado sustraerse al derecho se convierta en violencia que instaura nuevo derecho, durante un breve instante ha alzado la cabeza por encima del orden del destino. El "gran criminal" es admirado por el pueblo precisamente porque escapando al castigo se ha liberado del destino ${ }^{37}$, igual

33 GS II, 1, p. 188; trad. esp. p. 191.

34 ibidem.

35 GS II, 1, p. 186.

36 GS II, 1, p. 187.

37 GS II, 1, p. 183. 
que en Destino y carácter el héroe trágico mediante el silencio se había liberado por un momento del orden de la culpa ${ }^{38}$. A diferencia de la "violencia mítica", que es usada como medio (para un fin justo dado - en el derecho natural - o para fines jurídicos, es decir, para crear o mantener derecho - en el derecho positivo), la violencia que destruye derecho es un acto "inmediato" 39 , es decir, no tético, sin el carácter de medio para la posición (Setzung) de un nuevo orden o contenido externo, sino dirigido a la "suspensión" o "deposición"40 (Entsetzung) de cualquier contenido. Solo esta segunda violencia, que "viene a poner fin a las ambigüedades constructivas del derecho" 41 , como sostiene Benjamin en el ensayo sobre Karl Kraus, encarna la justicia.

"Si la violencia mítica inculpa y expía (verschuldend und sühnend) al mismo tiempo, la divina redime (entsühnend)" 42 . El destino "castiga" a la vez que "inculpa" porque ambas acciones coinciden en un solo acto práctico, el cual produce hermenéuticamente la culpa que necesita para desencadenar la violencia expiatoria y, así, consolidar el nexo compensatorio. La violencia divina, en cambio, no "expía" (sühnen) sino que "redime" (ent-sühnen), es decir, no libera de una culpa sino de la propia máquina compensatoria. La violencia divina, a diferencia de la jurídica, consiste en

la culpabilidad de la mera vida natural, que entrega a los seres vivos, inocentes y infelices, al castigo (Sühne), el cual 'expía' ('sühnt') su inculpación (Verschuldung) y redime (entsühnt) también al culpable, pero no de una culpa sino del derecho. Puesto que con la mera vida cesa el dominio del derecho sobre los seres vivos. ${ }^{43}$

38 GS II, 1, pp. 174-175.

39 GS II, 1, p. 198.

40 GS II, 1, p. 202. La violencia divina, a diferencia de la jurídica, no es un acto "performativo" sino "a-formativo", es decir, no posee la estructura de la "posición" sino de la supresión de cualquier contenido "puesto" previamente (cfr. Hamacher, W., "Afformative, Strike. Benjamin's 'Critique of Violence",, en Benjamin, A. y Osborne, P. (eds.), Walter Benjamin's Philosophy. Destruction and Experience. New York: Routledge, 1994, p. 115).

41 GS II, 1, p. 367; trad. esp. de J. Navarro Pérez, Obras. Libro II /vol. 2, p. 376.

42 GS II, 1, p. 199. La oposición entre expiación (sühnen) y redención (ent-sühnen) está marcada terminológicamente por el prefijo privativo "ent-". La "redención" sería entonces una especie de "desexpiación" que no libera de la culpa a través de la expiación, sino que libera de la propia expiación. En este sentido, la oposición sühnen / entsühnen calca la oposición Setzung / Entsetzung: la "posición" constructiva de la violencia jurídica y la "deposición" destructiva de la violencia divina.

43 GS II, 1, p. 200. El castigo de la "mera vida" funciona en la exposición como modelo de una posible vía de salida a la violencia jurídica: el castigo divino prefigura la liberación del castigo jurídico (productor de culpa). Sobre la violencia divina como liberación del orden del derecho véase Jacobson, E., Metaphysics of the Profane. The Political Theology of Walter Benjamin and Gershom Scholem. West Sussex: Columbia University Press, 2003, p. 217 ss. En la misma dirección, James R. Martel lee en el pasaje citado la intervención de una violencia anti-fetichista que destruye el falso ídolo del derecho (cfr. Martel, J. R., Divine Violence. Walter Benjamin and the Eschatology of Sovereignty. New York: Routledge, 2012, p. 52). 
En el castigo divino, que no golpea al culpable (como sí hace el castigo jurídico) sino a la vida natural o inocente del hombre (la "mera vida"), Benjamin detecta un acto que transgrede la lógica compensatoria del derecho. Se trata de un castigo que "expía", pero no de una culpa sino de la propia "inculpación" dictada por el derecho. Es, por tanto, un castigo "des-inculpante" o "des-expiante" (ent-sühnend). De nuevo, como en el caso del "destino" y el "carácter", la distinción entre las dos formas de Gewalt solo se dirime al redirigir ambas a la esfera "natural", donde aparecen como polos opuestos: la clausura dentro del orden de la culpa o la trascendencia de cualquier orden dado.

Pero el aspecto constructivo del derecho no se limita a instaurar/mantener el nexo culpa-castigo. Benjamin sostiene al final del ensayo que "la crítica de la violencia es ya la filosofía de su historia". La "crítica" es aquí entendida como destrucción de la "falsa" totalidad que constituye el destino, una totalidad que no hace referencia únicamente al nexo interno que establece un orden jurídico determinado sino también al nexo férreo de sucesión que regula el despliegue histórico de los distintos órdenes jurídicos. El afán constructivo se proyecta no solo sobre el derecho sino también sobre su historia, conformándola como un ciclo continuo de sustituciones de un orden jurídico por el siguiente. Frente al sucederse de la violencia que mantiene derecho y la violencia que lo destituye solo para instaurar uno nuevo, la violencia divina implica una interrupción de este continuum histórico44. Por eso la "crítica" de la violencia es inseparable de "la filosofía de su historia", porque describir el esquema temporal asociado al despliegue de la Gewalt y liquidar su endeble fundamento constructivo son una y la misma cosa.

\subsection{El capitalismo como destino}

Benjamin detecta la huella del "destino" no solo en el ámbito del derecho, tal como ya hemos visto, sino también en el de la economía, que muestra una análoga absorción de la realidad bajo un orden simbólico totalmente cerrado sobre sí mismo.

\footnotetext{
44 En las Tesis es posible reconocer una transposición al ámbito de la historia del nihilismo destructor contra la violencia jurídica. La violencia que suspende el derecho para instaurar uno nuevo no implica ninguna excepción histórica sino, al contrario, la continuación de la violencia mediante un ciclo continuo de sustituciones. Frente a este ciclo ininterrumpido, la violencia divina no suspende un derecho sino el continuum del derecho, bajo cualquiera de sus figuras. Análogamente, el "estado real de excepción" de la tesis VIII no implica la suspensión de una "norma" del devenir histórico (la linealidad del "progreso") para instaurar otra (la circularidad de la "catástrofe"), sino el gesto intransitivo o no tético de interrumpir el continuum entre las diferentes figuras de la normatividad histórica. Sobre esta línea de interpretación véase Tomba, M., La 'vera politica'. Kant e Benjamin: la possibilità della giustizia. Macerata: Quodlibet, 2006, pp. 242-248. En todo caso, como veremos, el nihilismo no es la última palabra de Benjamin en las tesis, que junto al momento destructivo contra la "falsa" totalidad articula un momento opuesto de construcción.
} 
El fragmento Capitalismo como religión (1921) analiza la tendencia de la economía capitalista al endeudamiento generalizado a partir del paralelismo entre la liquidación económica de las deudas y la expiación "religiosa" de las culpas, donde lo que Benjamin denomina ahora "religión" presenta los mismos rasgos que en sus trabajos anteriores poseía el "destino" 45 . En este sentido, algunas de las dificultades que presenta este denso fragmento (en algunos momentos al borde de lo ininteligible) pueden ser salvadas al abordarlo desde la óptica del "destino".

El trasfondo del breve fragmento lo constituye la "demoníaca ambigüedad" 46 del término Schuld, que en alemán significa tanto culpa como deuda. Esta ambigüedad había sido explotada productivamente por Nietzsche en La genealogía de la moral. Pero Benjamin, en vez de transponer la moral y la religión a la esfera de la economía (la "culpa" a la "deuda"), invierte la operación y transpone la economía a la esfera de la religión (la "deuda" a la "culpa"). El interés de los dos enfoques simétricos, en todo caso, reside en el gesto inactual que ambos dirigen contra la imagen ilusoria que cada época construye de sí misma: bien mostrando la contaminación impura del ámbito sublime de la moral por la economía (Nietzsche), bien describiendo el reencantamiento mítico que experimenta un mundo orgulloso de su desencanto profano, como la economía moderna (Benjamin).

La estrategia expositiva del fragmento es análoga a la empleada en Destino y carácter, ya que así como Benjamin había reconducido el "destino" de la esfera impropia de la religión a la del derecho, el "capitalismo" será reconducido ahora de la esfera económica a la de la religión. Está claro, por tanto, que "religión" no puede designar lo mismo en los dos casos. Si en el primero designaba un índice de liberación posible del círculo mágico del destino, ahora remite precisamente a éste último. No por casualidad los tres rasgos con los que Benjamin caracteriza el capitalismo como "religión" coinciden con los que antes definían el "destino".

El primer rasgo del capitalismo es su carácter cultual. "Todo, en él, tiene un significado solo en la inmediata referencia al culto, no conoce una dogmática especial, ni una teología" 47 . El capitalismo, como "culto", posee dos aspectos estrechamente relacionados: en primer lugar, implica la inscripción de los acontecimientos en un espacio simbólico que les confiere un significado; pero, en segundo lugar, esta inscripción semántica no funciona de forma meramente declarativa o teórica sino per-

\footnotetext{
${ }^{45}$ La continuidad del fragmento con la temática de Destino y carácter ha sido señalada por Hamacher, W., "Guilt history. Benjamin's sketch 'Capitalism as religion'”, en Diacritics, vol. 32, n' 3-4, 2002, pp. 85-87. Debería matizarse, en cambio, el enfoque de Michael Löwy, quien interpreta el fragmento como una polémica con las tesis de Max Weber sobre el capitalismo (cfr. "Anticapitalist Readings of Weber's Protestant Ethic: Ernst Bloch, Walter Benjamin, Georg Lukacs, Erich Fromm", en Logos. A Journal of Modern Society and Culture, vol. 9/1, 2010).

46 GS VI, p. 102.

47 GS VI, p. 100.
} 
formativamente, o sea, por medio de la práctica48. Igual que el destino y el derecho, el capitalismo es una "práctica interpretativa" que lee los acontecimientos como signos que reenvían a lo designado a través de un "nexo semántico". En Origen del Trauerspiel barroco (1923-25) Benjamin asociará este carácter performativo del culto a la tragedia, que se define como un "culto" que realiza de forma efectiva la acción que representa figuradamente, es decir, actualiza el evento trágico en vez de meramente representarlo como un referente externo ${ }^{49}$. La tragedia se define por la identidad inmediata entre representar y ser, signo y significado, a diferencia del Trauerspiel, que se dirige a la "exhibición repetible" 50 delante de un público diferente en cada ocasión y, por tanto, representa una acción dramática separable de cada una de sus puestas en escena ${ }^{51}$. Igual que el culto trágico, el culto capitalista confiere significado de forma "inmediata" 52 , las acciones son lo que representan y por tanto el contenido doctrinal es inseparable de la práctica, a diferencia de lo que ocurre en la "dogmática", que designa sus significados de forma declarativa o "mediata".

El segundo rasgo religioso del capitalismo es la "duración permanente del culto" 53, que no conoce "días festivos", ni siquiera una breve interrupción. El capitalismo, como el destino, es un orden sin exterioridad ni excepciones. Pero el rasgo decisivo es el tercero. El capitalismo es un culto de un tipo peculiar, "el primer caso de culto que no redime la culpa (entsühnenden) sino que produce culpa (verschuldenden)" 54 . El capitalismo se asemeja en esto al derecho, donde, como vimos, el castigo (la "inculpación jurídica") no liberaba de una culpa previa sino que la sintetizaba a posteriori para poder expiarla y así unir ambas (culpa y expiación)

48 El "culto" es una práctica cuyos efectos reales son independientes de la fe o creencia en cualquier doctrina (Fleischmann, C., Gewinn in alle Ewigkeit. Kapitalismus als Religion. Zürich: Rotpunktverlag, 2010, pp. 12-13).

49 GS I, 1, pp. 298-299.

50 GS I, 1, p. 298.

51 Esta distinción entre "culto" y "exhibición" (inmediatez performativa y distancia representativa) volverá a aparecer en el ensayo sobre la obra de arte, mediante la polaridad de la "mimesis" entre "apariencia" y "juego", "valor de culto" y "valor de exposición" (GS VII, 2, p. 368). En el arte "cultual" se confunden la apariencia sensible de la obra y el contenido inteligible que se encarna en ella, de forma que representar es ser, mientras que en el arte "expositivo" se produce una fractura que impide la identificación entre ambos. Sobre la polaridad de identificación/alteridad en el concepto de mimesis véase Desideri, F., "The mimetic bond: Benjamin and the question of technology", en Benjamin, A. (ed.), Walter Benjamin and Art. London: Continuum, 2005, p. 115; Lang, T., Mimetisches oder semiologisches Vermögen? Studien zu Walter Benjamins Begriff der Mimesis. Göttingen: Vandenhoeck \& Ruprecht, 1998, pp. 107-111.

52 GS VI, p. 100. Como señala Hamacher, "todo lo que tiene un significado es inmediatamente idéntico a lo que significa; el signo es inmediatamente lo significado" ("Guilt history. Benjamin's sketch 'Capitalism as religion'”, p. 87).

53 GS VI, p. 103.

54 GS VI, p. 100. 
mediante un nexo fatal. A diferencia del culto trágico, que liberaba al hombre de la coacción expiatoria aunque fuera solo de forma "ocasional" 55 , el culto capitalista lo somete a ella sin interrupción. "Una enorme conciencia de la culpa, que no sabe redimirse (entsühnen), recurre al culto no para expiar (zu sühnen) en él esta culpa, sino para hacerla universal" 56 . El capitalismo solo libera de la culpa a costa de someter al hombre a la máquina de la expiación, en un incesante ciclo que implica a todos en todo momento ${ }^{57}$.

Pero ¿en qué tipo de prácticas económicas piensa Benjamin cuando habla de la "religión" capitalista? Solo al final del ensayo ofrece algunos ejemplos dispersos, cuyo denominador común es precisamente la estructura "religiosa" de la compensación: la equivalencia económica de los bienes a través del dinero, a imagen y semejanza de la equivalencia religiosa entre culpa y castigo a través de la expiación. Benjamin observa que habría que investigar "a qué conexiones con el mito ha accedido el dinero en el curso de la historia" 58 . Y justo a continuación ofrece una serie de elementos a desarrollar: "Wergeld / Thesaurus de las buenas obras / Salario que se le adeuda (geschuldet) al sacerdote". Se trata de variaciones en torno al motivo de la compensación. El "Wergeld" era una institución del derecho medieval que estipulaba la entrega de una compensación monetaria a la víctima de una agresión violenta, con el fin de evitar así la venganza contra el agresor. El daño sufrido era compensado pacíficamente mediante una suma de dinero59. El Thesaurus designa una especie de prontuario con términos afines, en este caso, las buenas obras gra-

55 En Destino y carácter Benjamin señala que en el "culto del paganismo" (es decir, la tragedia griega), a diferencia del destino, era todavía posible la "resolución ocasional" de la culpa (GS II, 1, p. 178). Con el silencio moral el héroe trágico se libera de forma precaria "por primera vez de la niebla de la culpa" (GS II, 1, p. 174)

56 GS VI, p. 100.

57 El capitalismo no es por tanto el espacio de una culpa inexpiable, como sostiene Rasch ("Schuld als Religion", en Baecker, D. (hrsg.), Kapitalismus als Religion. Berlin: Erich Schmidt, 2003, p. 262). Lo que Benjamin critica al capitalismo no es la falta de expiación sino, al contrario, su exceso: necesita producir culpa continuamente pero solo para poderla expiar. Por eso el culto capitalista no "redime culpa" (entsühnenden) sino que "produce culpa" (verschuldenden) en el mismo acto de expiarla. El capitalismo no carece de "expiación", la liberación de la culpa, sino de "redención": la liberación del nexo entre culpa y expiación.

58 GS VI, p. 102. La analogía estructural entre el "dinero" y el "destino" se establece de forma explícita en el Passagen-Werk: "¿No se da una determinada estructura del dinero que solo se puede conocer por el destino, y una determinada estructura del destino que solo se puede conocer por el dinero?" (GS V, 1, p. 620 [O3, 6]; trad. esp. p. 497). Esta "estructura" común no es otra que el nexo semántico de compensación entre culpa y castigo, deuda y liquidación.

59 Véase la descripción histórica del Wergeld ofrecida por Simmel (cfr. Gesamtausgabe Band 6. Philosophie des Geldes. Frankfurt am Main: Suhrkamp, 1989, p. 482 ss). Para un análisis comparado del ensayo de Benjamin con las tesis sobre el capitalismo de Simmel véase Steiner, U., "Kapitalismus als Religion", en Lindner, B. (hrsg.), Benjamin Handbuch, Leben - Werk - Wirkung. Stuttgart: Metzler, 2011, pp. 169-170. 
cias a las cuales el hombre se hace digno (acreedor) de la salvación (adeudada) el día del Juicio, cuando el tribunal divino dicte la retribución final. El mismo motivo reaparece en la imagen del "balance como saber que redime y que liquida" 60 , es decir, el equilibrio contable entre deuda y crédito como un nexo compensatorio entre culpa y reparación.

En realidad todos estos ejemplos se condensan en uno solo: el "dinero" o el valor de cambio de la mercancía. El valor de cambio no es una propiedad natural del objeto sino el fruto de una convención social que inscribe los valores de uso en el universo simbólico del valor61. El valor de cambio funciona exactamente como un "nexo semántico" entre diferentes objetos: la equivalencia de valor que hace posible el intercambio entre bienes heterogéneos (aunque se trate de un intercambio peculiar, que no compensa dos magnitudes iguales sino que arroja un resto no compensado, el plusvalor). Esta operación de inscripción semántica no se lleva a cabo de forma declarativa sino mediante prácticas performativas (como diría Marx, "no lo saben pero lo hacen"). La producción o el intercambio de mercancías son acciones prácticas que responden exactamente a la definición benjaminiana del "culto", un acto que efectúa aquello que representa de forma figurada: la presencia del valor en los objetos. Así como el castigo jurídico toma la vida inocente y la "inculpa" (es decir, la introduce en la trama simbólica del destino) para poder "castigarla", las prácticas económicas se comportan de la misma manera: toman los bienes útiles y los inscriben en el universo imaginario del valor para así poder intercambiarlos. En ambos casos hallamos la circularidad entre representación y efectuación propia del "culto": es el mismo acto el que realiza la inscripción teórica y el que, a la vez, debe presuponerla para poder llevarse a cabo. En otras palabras, el intercambio presupone el valor de los bienes que él mismo establece, igual que el castigo presupone la culpabilidad de la vida natural a la vez que la produce.

El capitalismo produce valor como el derecho produce destino: a través de "prácticas interpretativas". El trabajo asalariado, la especulación con bienes de uso o el endeudamiento (público o privado) son prácticas de intercambio que presupo-

\footnotetext{
60 GS VI, p. 103.
}

61 Agamben interpreta la "religión" como una "forma de la separación", lo que le lleva a tomar la "religión capitalista" como un caso particular de esta separación, que se manifiesta, por ejemplo, en la escisión convencional entre valor de uso y valor de cambio (Profanazioni. Roma: Nottetempo, 2005, p. 98). Sin embargo, para Benjamin lo que define la religión no es la separación sino, al contrario, la identificación inmediata de los diferentes valores de uso con su valor. La religión capitalista no separa la esfera sensible de la inteligible sino que más bien las confunde en una unidad espuria. Por tanto, no es la "separación" sino la confusión indistinta entre esferas lo que caracteriza la concepción benjaminiana del mito. El mito inscribe las cosas en el interior de una relación de unidad simbólica entre el signo sensible y su significado, y se basa, por tanto, en la "ley de identidad" o la "conexión de elementos perceptibles y espirituales" (cfr. Menninghaus, W., Schwellenkunde. Walter Benjamins Passage des Mythos. Frankfurt am Main: Suhrkamp, 1986, pp. 62-68). 
nen el valor y a la vez lo producen. En la medida que otorgan una consistencia real a la ficción simbólica del valor, estas prácticas son estructuralmente necesarias para la reproducción del capitalismo. Así como la práctica jurídica del castigo era un medio para "fines jurídicos" (para instaurar/mantener el propio derecho), las prácticas económicas son ahora un medio para preservar el propio orden económico. El único fin en sí mismo de la sociedad capitalista es, por tanto, mantener el nexo culpa-expiación que teje la trama simbólica ("la red en la que nos encontramos"62) con la que el capitalismo captura el mundo de objetos.

El mercado, como el derecho, es una institución aparentemente procedimental, que no presupone ningún contenido normativo ni prescribe de antemano un bien común como fin de la acción de los individuos (qué necesidades deben satisfacerse o qué fines justos deben perseguirse). Bajo esta indumentaria profana Benjamin descubre que el mercado, como la religión o el destino, impone en realidad un contenido sustancial: su propia reproducción se convierte en la finalidad última de todas las prácticas económicas. El mercado "libre" y autorregulado, que libera a los hombres de cualquier tutela trascendente, en realidad los encadena a un nuevo telos común: la coacción a interpretar el mundo, y a conducirse en él, según dicta el horizonte simbólico del valor.

De esta manera, Benjamin se aproxima, con un aparato categorial propio, a una crítica del fetichismo semejante a la de Marx: la crítica del sacrificio de lo real (el trabajo particular, las necesidades concretas) al ídolo de lo imaginario (la intercambiabilidad y acrecentabilidad del valor). Como sostenía Marx, el fetichismo se convierte en la "religión de la vida diaria"63. La crítica del capitalismo como religión será en parte retomada en la descripción que el Passagen-Werk realiza del mundo capitalista del siglo XIX, donde la "fantasmagoría" designa de nuevo una hermenéutica performativa que absorbe las innovaciones del mundo industrial en un espacio simbólico totalizante ${ }^{64}$. Sin embargo, en el Passagen-Werk este espacio ya no estará estructurado por el modelo religioso de la compensación sino por el modelo teológico-místico de la encarnación, es decir, la inyección de un soplo de vida espiritual en el mundo de objetos desencantados del siglo XIX, que se inspira ahora en

\footnotetext{
62 GS VI, p. 100. La imagen de la "red" había sido utilizada en Destino y carácter para describir, precisamente, el nexo culpa-expiación propio del destino: "la felicidad libera a quien es feliz de la concatenación de los destinos y de la red del propio" (GS II, 1, p. 174).

63 Marx, K., El Capital. Libro III - Tomo III. Madrid: Akal, 2012, p. 285. También en Marx es posible encontrar una crítica del capitalismo como religión, la cual adopta varios niveles de sentido. Uno de ellos remite precisamente a la "lógica sacrificial" del fetichismo (cfr. Dussel, E., Las metáforas teológicas de Marx. Estella: Verbo Divino, 1993, pp. 213-223).

64 Sobre un posible paralelismo entre los rasgos "religiosos" del capitalismo y la "fantasmagoría" de la mercancía en el siglo XIX véase Caygill, H., "Non-messianic Political Theology in Benjamin's 'On the Concept of History"', en Benjamin, A. (ed.), Walter Benjamin and History. London: Continuum, 2005, p. 225.
} 
un aspecto diferente del fetichismo de la mercancía (la parusía del valor de cambio en el cuerpo místico de la mercancía). En todo caso, la fantasmagoría sigue siendo un "culto" que lee los fenómenos como signos que están ligados con su significado mediante la unidad indistinta característica del mito.

\section{La redención como construcción dialéctica}

Hemos mostrado en la sección anterior la analogía estructural que existe entre los trabajos que Benjamin dedicó al tema del "destino". Tanto el derecho como el capitalismo son solo diferentes manifestaciones de la clausura semántica que afecta a las acciones y las cosas bajo la lógica inapelable de la compensación. A pesar de las transformaciones que experimenta el pensamiento de Benjamin entre los años veinte y los años treinta existe una clara continuidad entre ambos momentos, apreciable, por ejemplo, en la afinidad que presenta la crítica del "destino" con la crítica del "progreso". En efecto, ya vimos en la primera sección que Benjamin percibía en el progreso una práctica hermenéutica que inscribe a las diferentes generaciones en la trama semántica de la compensación entre la infelicidad pasada y la felicidad futura. A través de la subsunción de pasado y presente bajo el continuum lógico de culpa y expiación, la doctrina del progreso reproduce el orden mítico del destino. De hecho, la proyección de la lógica compensatoria del destino sobre el ámbito de la historia es algo que Benjamin ya había ensayado tentativamente en algunos fragmentos contemporáneos a sus trabajos de crítica del derecho ${ }^{65}$. Esta línea de reflexión es recuperada de forma indirecta en el Passagen-Werk y con especial énfasis en la tesis II, donde Benjamin retoma el hilo de su anterior crítica al destino para proyectarla sobre el ámbito de la historia.

Según hemos visto en la primera sección, en la tesis II Benjamin oponía el "progreso" a la "redención". En esta oposición resuena una polaridad que aparece recurrentemente en sus anteriores trabajos sobre el "destino". Así, por ejemplo, Destino y carácter oponía el tiempo del destino - marcado por la sucesión necesaria entre los dos términos ligados por el nexo compensatorio - y el "tiempo de la redención" 66 , en el que el hombre accede, aunque sea solo por un momento, a una felici-

65 Por ejemplo, en un fragmento de 1918 Benjamin definía la "culpa" como "la categoría más elevada" de la historia universal: "cada momento de la historia universal es inculpado y produce culpa (verschuldet und verschuldend). [...] Sin embargo un estado del mundo solo es culpable (en referencia a uno posterior)" (GS VI, p. 92). En otro fragmento (1920-21) Benjamin contrapone una concepción jurídica de la historia basada en la "retribución" (Vergeltung) a una concepción moral fundada sobre el "perdón" (Vergebung). En la primera, "el día del juicio" es "el término en el cual [...] se da inicio a toda retribución" (GS VI, p. 98), mientras que en la segunda la retribución se halla "incesantemente en fuga hacia el futuro", de forma que el "perdón" aplaza sine die la aparición de la "violencia retributiva" (vergeltende Gewalt).

66 GS II, 1, p. 176. 
dad liberada de la culpa. Análogamente, Hacia la crítica de la violencia oponía la violencia mítica del derecho a la "violencia divina", que redime no de una culpa sino del propio derecho (la coerción compensatoria). El "carácter" y la "violencia divina" suponen, por tanto, dos figuras del momento destructivo que venía a liquidar el falso constructo pergeñado por el destino 67.

Pero el nihilismo destructor no es la última palabra de Benjamin, que en las Tesis lleva a cabo una modulación del momento destructivo hacia un momento constructivo. Si en los años veinte había predominado en su pensamiento la antítesis insalvable entre el orden profano y el divino (de forma que el ingreso en el reino mesiánico requería la liquidación apocalíptica de la caducidad terrenal), las tesis elaboran la noción de un cumplimiento a la vez mundano y extramundano ${ }^{68}$. La "redención" implica ciertamente una suspensión de la falsa totalidad de la historia (el continuum del progreso), pero, lejos de conformarse con el momento destructivo, mantiene una aspiración a la reunión constructiva de los diferentes momentos históricos en una "verdadera" totalidad, la cual compendia sus auténticas posibilidades de realización histórica.

La totalidad que la "redención" trata de construir se compone de dos momentos opuestos, cuya articulación conjunta resulta especialmente visible en la tesis II. Como ya anunciábamos en la sección I, esta tesis constituye el punto de intersección de dos vectores pertenecientes a la reflexión previa de Benjamin: por un lado, la crítica al orden del "destino", y, por otro, la crítica a la "cosificación" del pasado. Para reunir estos dos momentos Benjamin recurre a la teoría "dialéctica" del conocimiento elaborada previamente en el libro sobre el Barroco. La tensión mutua que el prólogo epistemo-crítico establecía entre dos modos opuestos de relación de los fenómenos y su verdad - la expresividad de los hechos y la inexpresividad de la idea - es reconocible ahora en la dialéctica entre el pasado y la felicidad. En la tesis II la felicidad aparece como una posibilidad inseparable de los fenómenos del pasado pero, al mismo tiempo, como un excedente de sentido irreductible a ellos, a la vez presente y ausente de los hechos históricos.

En primer lugar, "la idea de la felicidad"69 (es decir, nuestra concepción o representación de ella) está inscrita en los acontecimientos de nuestro propio pasado.

67 En Capitalismo como religión la función de oposición al "destino" es reconocible en la referencia final al "socialismo" (Marx) y al "superhombre" (Nietzsche), que funcionan como figuras posibles de un más allá del orden capitalista del valor (GS VI, pp. 101-102).

${ }^{68} \mathrm{La}$ lectura en clave apocalíptica del mesianismo de Benjamin (como, por ejemplo, la realizada por Jacob Taubes) sostiene una estricta separación entre el orden profano y el divino. Sin embargo, este antinomismo olvida la tensión dialéctica del pensamiento benjaminiano que, a la vez que rechaza la caducidad terrenal, está comprometido con ella en la búsqueda de una felicidad profana (cfr. Tagliacozzo, T., "Jacob Taubes interprete della teologia politica di Benjamin", en Paradigmi, Anno XIX, n. 56, maggio - agosto 2001, pp. 309-311). Sobre la "teología dialéctica" de Benjamin véase Jacobson, E., op. cit., p. 31 ss.

69 GS I, 2, p. 693; trad. esp. p. 306. 
Solo la hallamos "en el aire que hemos respirado, con hombres con los que hubiéramos podido conversar, con mujeres que hubiesen podido entregársenos" 70 . La felicidad posible para nosotros no es una abstracción atemporal e independiente de nuestras vivencias, sino que solo se hace presente por medio de una imagen "teñida enteramente por el tiempo al que el decurso de nuestra existencia nos ha asignado de una vez por todas"71. A cada época le corresponde una felicidad particular, a la que solo tiene acceso como el envés negativo de sus actos realizados y no logrados.

Por eso no podemos envidiar el futuro, porque la única felicidad que podemos desear está anclada a los hechos de un tiempo determinado, mientras que la felicidad futura, en la medida que depende de hechos que todavía no han tenido lugar, es por definición informe y abstracta. "La general falta de envidia de todo presente respecto a su futuro" 72 solo puede sentirla quien no concibe la felicidad como una experiencia suprahistórica, igualmente disponible para cualquier época, sino quien ha roto con la máquina de la compensación y no cree en la equivalencia entre la felicidad de dos momentos históricos distintos. La "envidia" del futuro, en cambio, corresponde al punto de vista del progreso, para el que no hay momentos cualitativamente privilegiados sino solo diferentes expresiones de una única magnitud temporal (el "tiempo vacío y homogéneo"73).

El progreso se basa en el mismo tiempo descualificado que en Destino y carácter caracterizaba el destino. "El nexo de la culpa es temporal de forma inauténtica, completamente diferente por su tipo y por su medida del tiempo de la redención [...] Se puede hacer a este tiempo simultáneo con cualquier otro tiempo no presente" 74 . El "tiempo del destino" subsume la singularidad de cada instante bajo determinaciones abstractas válidas para cualquier momento, como las de "culpa" y "expiación". Por eso, como afirma Benjamin en otro fragmento, "en el fondo la retribución es indiferente al tiempo"75, es decir, a la concreción de cada momento temporal, que es aplanada en favor de una equivalencia entre dos magnitudes abstractas.

Pero la felicidad no solo es inseparable de los fenómenos de cada momento histórico sino que, a la vez, es irreductible a ellos. Las experiencias de nuestro pasado aluden a la felicidad como los signos designan un significado lejano e inalcanzable. "El pasado lleva un índice secreto que no deja de remitirlo a la redención"76. Este peculiar modo de indicación o referencialidad es precisamente lo que en el prólogo epistemo-crítico Benjamin denominaba "inintencionalidad", es decir, la condición

\footnotetext{
70 ibidem.

71 ibidem.

72 ibidem.

73 GS I, 2, p. 701 (tesis XIII).

74 GS II, 1, p. 176; trad. esp. pp. 179-180 (traducción modificada).

75 GS VI, p. 97.

76 GS I, 2, p. 693.
} 
potencial de la idea, que nunca puede actualizarse integralmente en ningún conjunto de hechos. La felicidad a la que apunta el pasado permanece en un estado de virtualidad que excede la traducción exhaustiva en términos empíricos. La "débil fuerza mesiánica", que evita la identificación de lo potencial con lo actual, del reino divino y el profano, alude entonces a una "debilidad" que es precisamente la fuerza del mesianismo ${ }^{77}$. La felicidad adopta en las tesis la misma consistencia huidiza que la teoría del conocimiento del libro sobre el Barroco asociaba a la "idea". Benjamin trata así de extraer el pasado de las garras del objetivismo historicista, que reduce la dimensión potencial de los hechos a una sola posibilidad, la que tuvo efectivamente lugar.

Podría decirse entonces que la tesis II desarrolla una crítica "dialéctica", dirigida simultáneamente contra el tiempo sin cualidades del progreso y contra la totalización historicista del pasado. Esta tensión "dialéctica" entre opuestos proporciona asimismo el trasfondo de la polémica con Horkheimer sobre el problema de lo "inconcluso" de la historia:

La injusticia pasada ha sucedido y está conclusa (abgeschlossen). Los golpeados han sido realmente golpeados. Si se toma lo inconcluso (Unabgeschlossenheit) con toda seriedad, entonces hay que creer en el juicio final. Quizá respecto de lo inconcluso exista una diferencia entre lo positivo y lo negativo, de modo que únicamente la injusticia, el horror y el dolor del pasado sean irreparables. La justicia practicada, las alegrías, las obras poseen otra relación con el tiempo, pues su carácter positivo queda ampliamente negado por la caducidad. 78

El fragmento, incluido en el Passagen-Werk, forma parte de la carta en la que Horkheimer respondía a algunas de las formulaciones contenidas en el ensayo sobre Eduard Fuchs. En particular, Horkheimer se refiere a la crítica que Benjamin dirige al historicismo por considerar las obras del pasado como algo "concluso" o "cerrado"79 (abgeschlossen). Horkheimer no acepta esta crítica, ya que si el pasado fuese

\footnotetext{
${ }^{77}$ La imposibilidad de un acceso pleno a la esfera del significado previene contra las ilusiones de una plena realización intramundana de la historia. Esta imposibilidad es lo que confiere su peculiar "debilidad" a la "referencialidad mesiánica", que no es una "debilidad" accidental, que pudiera ser superada en circunstancias más favorables, sino estructural o constitutiva (Hamacher, W., "'Now': Walter Benjamin on Historical Time", en Benjamin, A. (ed.), op. cit., p. 45).

78 GS V, 1, p. 589 (N8, 1); trad. esp. p. 473.

79 GS II, 2, p. 477. El fragmento se halla en el "excurso sobre la conclusión (das abgeschlossene) o apertura de las obras del pasado" (GB V, p. 486 [carta a Benjamin del 16 marzo de 1937]) que acompañaba los comentarios de Horkheimer sobre el Fuchs, que Benjamin le había enviado el 28 de febrero (GB V, p. 463). La mención a la "conclusión" del pasado alude al pasaje del Fuchs en el que Benjamin critica el historicismo por considerar "las obras del pasado" como "conclusas" (cfr. Tiedemann, R., "Historischer Materialismus oder politischer Messianismus", en Bulthaup, P. (ed.), Materialien zu Benjamins Thesen 'Über den Begriff der Geschichte'. Frankfurt am Main: Suhrkamp,
} 
algo "inconcluso" (unabgeschlossen), como sostiene Benjamin, entonces debería admitirse que no es "irreparable", es decir, que existe la posibilidad de una reparación o compensación de "lo negativo" del pasado (la "injusticia" y el "dolor") por "lo positivo" del presente (la "justicia" y las "alegrías"). Pero admitir la "reparación" del pasado implicaría un regreso injustificable al orden del mito, que Horkheimer ilustra con la mención al "juicio final" (el tribunal que dicta la expiación de las culpas). Por tanto, el dolor pasado debe permanecer "concluso" o "irreparable", es decir, sin compensación.

Sin embargo, al pretender que la crítica anti-historicista de Benjamin recae en una concepción mítica de la historia, Horkheimer parece no captar la ambivalencia "dialéctica" del pensamiento benjaminiano, opuesta tanto al carácter "concluso" del pasado como a la idea mítica de una "reparación" entre pasado y presente (precisamente el rasgo típico del "destino"). Superar la clausura positivista del pasado sin caer en una hermenéutica indiferente a los hechos es justamente el doble objetivo crítico de la noción de "rememoración" (Eingedenken), la cual posee una estructura dialéctica análoga a la de la categoría de "redención":

La historia no es solo una ciencia, sino no menos una forma de rememoración. Lo que la ciencia ha 'establecido' ('festgestellt'), puede modificarlo la rememoración. La rememoración puede hacer de lo inconcluso (la felicidad) algo concluso, y de lo concluso (el dolor) algo inconcluso. Esto es teología. 80

Benjamin alinea aquí a Horkheimer con la "ciencia" historicista, que "establece" o "fija" el pasado bajo un significado válido de una vez por todas. Un modo de aproximarse al correctivo que la "rememoración" realiza al historicismo consistiría en seguir la pista de la "teología", tal como Benjamin sugiere lacónicamente. Otra vía, solo aparentemente alternativa, pasaría en cambio por mostrar que los dos polos de la noción de "rememoración" - la transformación de lo inconcluso en concluso y viceversa - no son sino una reformulación de los dos momentos opuestos presentes en su anterior teoría "dialéctica" del conocimiento 81.

1975, pp. 87-89; Bonola, G. y Ranchetti, M. (eds.), Sul concetto di storia. Torino: Einaudi, 1997, p. 272). Benjamin, en su respuesta a Horkheimer (GB V, pp. 487-488 [carta del 28 de marzo]) dejará a un lado el tema central de la polémica entre ambos. Por tanto, el fragmento N8,1 y la tesis II pueden considerarse como la respuesta indirecta de Benjamin a Horkheimer sobre el problema de la "conclusión" de la historia.

80 GS V, 1, p. 589 (N8, 1); trad. esp. p. 473.

81 Que "teología" y "dialéctica" no son vías alternativas sino dos caras de lo mismo es algo que se entrevé en la reflexión de Gershom Scholem sobre la "honda dialéctica" que atraviesa el judaísmo. Como señala Scholem, la doctrina judía de la creación divina del mundo se halla impulsada por un "doble movimiento": la "emanación" de la esencia divina (En-sof) y la "autolimitación" de Dios (tsimtsum). De esta forma el judaísmo consigue preservar la ilimitada plenitud de Dios (incluyendo en su propia esencia a todo lo creado) y, a la vez, la radical alteridad entre ambos. La divinidad irradia su 
La continuidad subterránea que une categorías como "redención" o "rememoración" con la teoría benjaminiana del conocimiento se capta con mayor claridad al atender a la estructura polar del "origen", una de las categorías claves del prólogo epistemo-crítico ${ }^{82}$. El "origen" es "una categoría plenamente histórica", inscrita en el propio devenir histórico, pero sin embargo no pertenece por entero a la realidad efectiva porque "no tiene nada en común con la génesis" 83 (es decir, con un proceso de desarrollo empírico). El origen, siendo inseparable del medium inmanente de los fenómenos históricos, a la vez permanece exterior a su mero despliegue fáctico. La inversión entre lo inconcluso y lo concluso que define la "rememoración" reformula, por tanto, con una diversa declinación, la "dialéctica que es intrínseca al origen" 84 . Esta dialéctica "quiere ser entendida como restauración, como restitución por un lado, y por el otro, y justo por eso mismo, como algo imperfecto e inconcluso (Unabgeschlossenes)" 85 . La exposición histórica del "origen" de una cierta época, en primer lugar, pone el acento sobre la potencialidad semántica de los hechos del pasado y, de esta manera, les confiere una mayor "inconclusión" (contra la pretensión historicista de reducirlos a la positividad "conclusa" de lo realmente ocurrió). Pero simultáneamente confiere al presente una mayor concreción o "conclusión", al descubrir en los fenómenos particulares que lo componen el soporte empírico de las posibilidades que le pertenecen de forma específica (contra la doctrina del progreso, que hace de las posibilidades históricas un universal abstracto y atemporal). A la virtualización del pasado - su devenir "inconcluso" - le corresponde una concretización del presente - su devenir "concluso". A una mayor inexpresividad del significado del pasado le sigue una mayor expresividad de los hechos del presente.

A la luz de la dialéctica del "origen", por tanto, se aprecia mejor la tensión entre polos opuestos que caracteriza la noción de "redención", con la que Benjamin se opone tanto a la cruda facticidad del historicismo como a la abstracción sin fricción

propia infinitud sobre la creación, pero a la vez se retira para no confundirse de forma panteísta con ella (Scholem, G., Conceptos básicos del judaísmo. Dios, Creación, Revelación, Tradición, Salvación. Madrid: Trotta, 1998, pp. 70-73; sobre la "dialéctica interna al concepto de creación" en el judaísmo véase del mismo autor "Diez tesis ahistóricas sobre la Cábala", en "...todo es cábala”. Diálogo con Jörg Drews. Madrid: Trotta, 2001, pp. 69-72). Por lo tanto, la dialéctica entre el plano divino y el de la creación es estructuralmente análoga a la tensión entre el momento de expresividad e inexpresividad que en el libro sobre el Barroco mantenían las ideas y los fenómenos.

82 Sobre la analogía entre la noción benjaminiana de "origen" y la concepción cabalista del tsimtsum véase Desideri, F., La porta della giustizia. Saggi su Walter Benjamin. Bologna: Pendragon, 1995, pp. 19-21.

83 GS I, 1, p. 226. Sobre la oposición de identidad y diferencia presente en el "origen" véase Weber, S., "Genealogy of Modernity: History, Myth and Allegory in Benjamin's Origin of the German Mourning Play", en Modern Language Notes, Vol. 106, No. 3, April 1991, pp. 470-472; Gabrielli, P., Sinn und Bild bei Wittgenstein und Benjamin. Bern: Peter Lang, 2004, pp. 478-479.

84 ibidem.

85 ibidem. 
con la realidad del destino. Por un lado, el pasado es "concluso" cuando se inmoviliza en un aspecto unívoco y común para todos los tiempos venideros. Consiguientemente, hacer "de lo concluso (el dolor) algo inconcluso" implicaría, según la intención de Benjamin en el Fuchs, des-cosificar el pasado y abrir los fenómenos a una recepción múltiple y no codificada. El pasado recupera así su dimensión potencial, como índice de una reserva de sentido irreductible a cualquier presencia empírica. Por otro lado, hacer "de lo inconcluso (la felicidad) algo concluso" implicaría comprender la felicidad como algo condicionado históricamente. Frente a una historia indefinidamente abierta, en la que la felicidad sobrevuela como una posibilidad abstracta cada uno de sus momentos, la "redención" concibe la felicidad como una figura estrictamente delimitada por los acontecimientos de cada presente.

La noción de "redención", por lo tanto, muestra la misma estructura "dialéctica" que el "origen" o la "rememoración". El pasado es "inconcluso" en la medida que posee un índice que apunta a algo otro respecto de su mera presencia empírica; aunque a la vez esa alteridad no toma la forma de un universal suprahistórico sino que está ligada de forma única a cada presente, el cual por tanto es "concluso", en la medida que no puede ser compensado o "reparado" en el futuro. La "redención" modifica el pasado des-inculpándolo, es decir, revelando tras la positividad del dolor sufrido la imagen virtual de una felicidad posible; pero, a la vez, modifica el presente volviéndolo in-expiable, es decir, portador de una felicidad que no comparte con ningún futuro. Parafraseando a Benjamin podría decirse que la redención "redime" el pasado, pero no de una injusticia sino de la historia universal (del propio nexo entre injusticia y retribución).

Sin embargo, a diferencia de la crítica al "destino", la "redención" no designa ahora únicamente un momento destructivo (la interrupción del continuum histórico) sino que la disolución de la "falsa" construcción prepara la aparición de una distinta trama de la historia, que solo captamos por medio de una "verdadera" construcción, es decir, una construcción "dialéctica", en la que el trabajo del historiador muestra la conexión secreta que une la potencialidad de un pasado inocente y el perfil concreto de la felicidad del presente. La "redención", por tanto, más que oponerse a la lógica de la compensación la depura de su contenido mítico, ya que lo que busca es restituir la tensión entre lo actual y lo potencial en el interior de cada momento histórico y, por tanto, compensar tanto el exceso positivista de actualidad en el pasado como el predominio idealista de la potencialidad en el presente. Benjamin rechaza por igual las dos variantes opuestas de la "falsa" totalidad de los fenómenos, la que rebaja las expectativas de lo posible hasta hacerlas coincidir con lo real y la que subsume la diversidad de momentos históricos bajo una única norma vinculante. Entre los dos extremos Benjamin intenta abrir una "vía" o "camino" aquello que la tradición filosófica alguna vez designó con el nombre de dialéctica - para pensar de otra manera la posibilidad del cambio histórico. 


\section{Bibliografía}

Agamben, G.: Profanazioni. Roma: Nottetempo, 2005.

Assmann, J.: Historia y mito en el mundo antiguo. Los orígenes de la cultura en Egipto, Israel y Grecia. Madrid: Gredos, 2011.

Benjamin, W.: Gesammelte Schriften (hrsg. von R. Tiedemann und H. Schweppenhäuser), I-VII Bände. Frankfurt am Main: Suhrkamp, 1972-1989.

Benjamin, W.: Gesammelte Briefe (hrsg. von C. Gödde und H. Lonitz), I-VI Bände. Frankfurt am Main: Suhrkamp, 1995-2000.

Bonola, G. y Ranchetti, M. (eds.): Sul concetto di storia. Torino: Einaudi, 1997.

CAYgill, H.: "Non-messianic Political Theology in Benjamin's 'On the Concept of History", en Benjamin, A. (ed.), Walter Benjamin and History. London: Continuum, 2005, pp. 215-226.

Desideri, F.: "The mimetic bond: Benjamin and the question of technology", en Benjamin, A. (ed.), Walter Benjamin and Art. London: Continuum, 2005, pp. $108-120$.

Desideri, F.: La porta della giustizia. Saggi su Walter Benjamin. Bologna: Pendragon, 1995.

Dussel, E.: Las metáforas teológicas de Marx. Estella: Verbo Divino, 1993.

Fenves, P.: The Messianic Reduction. Walter Benjamin and the Shape of Time. Stanford: Stanford University Press, 2011.

Fleischmann, C.: Gewinn in alle Ewigkeit. Kapitalismus als Religion. Zürich: Rotpunktverlag, 2010.

Gabrielli, P.: Sinn und Bild bei Wittgenstein und Benjamin. Bern: Peter Lang, 2004.

HAMAcheR, W.: “Now': Walter Benjamin on Historical Time”, en Benjamin, A. (ed.), Walter Benjamin and History. London: Continuum, 2005, pp. 38-68.

HAMACHER, W.: "Guilt history. Benjamin's sketch 'Capitalism as religion", en Diacritics, vol. 32, n 3-4, 2002, pp. 81-106.

HAMAcheR, W.: "Afformative, Strike. Benjamin's 'Critique of Violence", en Benjamin, A. y Osborne, P. (eds.), Walter Benjamin's Philosophy. Destruction and Experience. New York: Routledge, 1994, pp. 110-138.

Hanssen, B.: "Philosophy at Its Origin: Walter Benjamin's Prologue to the Ursprung des deutschen Trauerspiels", en Modern Language Notes, vol. 110, No. 4, September 1995, pp. 809-833.

Jacobson, E.: Metaphysics of the Profane. The Political Theology of Walter Benjamin and Gershom Scholem. West Sussex: Columbia University Press, 2003.

LANG, T.: Mimetisches oder semiologisches Vermögen? Studien zu Walter Benjamins Begriff der Mimesis. Göttingen: Vandenhoeck \& Ruprecht, 1998. 
Löwy, M.: “Anticapitalist Readings of Weber's Protestant Ethic: Ernst Bloch, Walter Benjamin, Georg Lukacs, Erich Fromm”, en Logos. A Journal of Modern Society and Culture, vol. 9/1, 2010.

Marquard, O.: Las dificultades con la filosofía de la historia. Valencia: PreTextos, 2007.

Marquard, O.: Apología de lo contingente. Valencia: Edicions Alfons el Magnànim, 2000.

MARTEL, J. R.: Divine Violence. Walter Benjamin and the Eschatology of Sovereignty. New York: Routledge, 2012.

MARX, K.: El Capital. Libro III - Tomo III. Madrid: Akal, 2012.

Menninghaus, W.: Schwellenkunde. Walter Benjamins Passage des Mythos. Frankfurt am Main: Suhrkamp, 1986.

Nietzsche, F.: La genealogía de la moral. Madrid: Alianza, 2008.

Nietzsche, F.: Aurora. Meditaciones sobre los prejuicios morales. Palma de Mallorca: Jose J. de Olañeta, 2003.

RASCH, W.: "Schuld als Religion", en Baecker, D. (hrsg.), Kapitalismus als Religion. Berlin: Erich Schmidt, 2003.

Simmel, G.: Gesamtausgabe Band 6. Philosophie des Geldes. Frankfurt am Main: Suhrkamp, 1989.

Scholem, G.: “...todo es cábala”. Diálogo con Jörg Drews. Madrid: Trotta, 2001.

Scholem, G.: Conceptos básicos del judaísmo. Dios, Creación, Revelación, Tradición, Salvación. Madrid: Trotta, 1998.

SteIner, U.: "Kapitalismus als Religion", en Lindner, B. (hrsg.), Benjamin Handbuch, Leben - Werk - Wirkung. Stuttgart: Metzler, 2011, pp. 167-174.

STEINER, U.: "Das "Höchste wäre: zu begreifen, daß alles Fachtische schon Theorie ist”. Walter Benjamin ließt Goethe”, en Zeitschrift für deutsche Philologie, 121, 2002, pp. 265-284.

TAgliacozzo, T.: “Jacob Taubes interprete della teologia politica di Benjamin", en Paradigmi, Anno XIX, n. 56, maggio - agosto 2001, pp. 283-311.

TiedemanN, R.: "Historischer Materialismus oder politischer Messianismus", en

Bulthaup, P. (ed.), Materialien zu Benjamins Thesen 'Über den Begriff der Geschichte’. Frankfurt am Main: Suhrkamp, 1975, pp. 77-121.

Tiedemann, R.: Studien zur Philosophie Walter Benjamins. Frankfurt am Main: Suhrkamp, 1973.

TomBA, M.: La 'vera politica'. Kant e Benjamin: la possibilità della giustizia. Macerata: Quodlibet, 2006.

Weber, S., "Genealogy of Modernity: History, Myth and Allegory in Benjamin's

Origin of the German Mourning Play”, en Modern Language Notes, Vol. 106, No. 3, April 1991, pp. 465-500. 
Weigel, S.: Walter Benjamin. Die Kreatur, das Heilige, die Bilder. Frankfurt am Main: Fischer, 2008.

José Luis Delgado

Universidad de Barcelona

jluisdelgado@hotmail.com 